\title{
Comparative Study of the Clinical Outcome of Retrograde Laparoscopic Appendicectomy Using a Single Polymer Clip for Complicated Versus for Non-Complicated Appendicitis
}

\section{Basem Mohamed Sieda*}

Department of General Surgery, Zagazig University Hospitals, Zagazig, Egypt

\begin{abstract}
Objective: To evaluate the clinical outcome of using single Hem-O-Lock polymer clip and compare technical feasibility of retrograde laparoscopic appendicectomy for complicated versus non-complicated appendicitis in adults.

Methods: A single institute prospective study of 78 patients presenting with acute appendicitis, Only 60 patients were eligible, 3 port retrograde laparoscopic appendicectomy were used in both groups and a single Hem-O-Lock polymer clip applied to secure the appendicular stump. The primary clinical outcome was the severity of pain at 1-7 days. Secondary outcomes included the duration of operation (minutes), procedure-related complications, conversion rates and length of hospital stay.

Results: Four patients (15.4\%) were converted to open surgery, three in group I and one patient in group II. Four patients developed postoperative complications, three in group I and one patient in group II. Operative time was less in Group II. The difference in conversion rates and post-operative complication between two groups is statisticallynot significant with a $P$ value $>0.05$.
\end{abstract}

Conclusion: Retrograde laparoscopic appendicectomy using single polymer clip make easy access operating complicated as well as non-complicated appendicitis.

Keywords: Complicated appendicitis; Polymer clips; Laparoscopic appendicectomy

\section{Introduction}

The real challenge in laparoscopic appendicectomy (LA) is considered to be those patients where the appendix is complicated forming a mass, abscess, gangrenous or there are firm adhesions making its skeletonization difficult by laparoscopic means [1-3]. The proper management technique of complicated appendicitis had been more controversial. LA in complicated cases can be technically demanding procedure thus necessitated a special approach to deal with. Retrograde appendicectomy allows early access to the appendicular base and prevent inadvertent injury to cecum especially in cases where the tip is buried in a mass $[4,5]$. Hem-o-lock clip is a non-absorbable polymer clip with a lock-engagement feature as well as teeth within the jaws, all of which provide greater security [6,7]. Using single polymeric clip for the closure of appendicular stump is a safe, feasible and easy applicable and can be a standard method in LA for complicated and non-complicated appendicitis for all age [8].

\section{Patient and method}

Between August 2012 and April 2014, a 78 patients presenting to our University Hospitals in emergency unit (ER) with acute appendicitis were diagnosed by (clinical examination, fever, elevated total leukocyte count (TLC), elevated C Reactive protein (CRP), Pelviabdominal Ultrasonography (US) and finally the most diagnostic issue is the CT abdomen and pelvis which issued for patients with suspected complicated appendix when the US is not conclusive or negative. Patients were categorized into two groups, Group I, included 26 patients with complicated appendicitis (appendicular mass, gangrenous and perforated appendix). Group II included 34 patients with non-complicated appendicitis.

Inclusion criteria: All patients with acute appendicitis above 18 years old were included in the study.
Exclusion criteria: Included patients with previous pelvic surgery, pediatric and old aged patients, Previous open abdominal surgery through midline surgery, patients with markedly inflamed or gangrenous appendicular base, patients unable to consent or refused laparoscopic intervention and patients unfit for anesthesia.

All patients signed consent for possible conversion to open technique.

\section{Technique}

A 3 port were used; the first or the optical trocar was a $10 \mathrm{ml}$ trocar, the other 2 trocars inserted under complete vision. The second port at the left mid-clavicular line $10 \mathrm{~mm}$ at the level between the umbilicus and supra-pubic port for the introduction of clip applier and a third port $5 \mathrm{~mm}$ supra-pubic for the grasper.

Firstly the appendix base and tip were identified and visualized, any part of the appendicular shaft were holded with the grasper, especially in the complicated appendix (Figures 1 and 2), Told's line incised for dissection of appendicular mass or for drainage of an appendicular abscess. The appendix is freed, a window was done in the mesoappendix beside and adherent to the base, clip applier introduced and fired a single Hem-O-Lock polymer clip (L.XL clips) at the appendicular base (Figures 3 and 4), Patients with markedly

*Corresponding author: Basem Mohamed Sieda, MD, Department of General Surgery, Zagazig University hospitals, Zagazig, 13 El Hasn Ben Elhaithem st, El Kawmia, Zagazig, Sharkia, Egypt, Tel: 201000089500, 201200016007; E- mail: drbasemsieda@gmail.com,drbassemmostafa@yahoo.com

Received January 17, 2016; Accepted March 02, 2016; Published March 11 2016

Citation: Sieda BM (2016) Comparative Study of the Clinical Outcome of Retrograde Laparoscopic Appendicectomy Using a Single Polymer Clip for Complicated Versus for Non-Complicated Appendicitis. Surgery Curr Res 6: 263. doi:10.4172/2161-1076.1000263

Copyright: (C) 2016 Sieda BM. This is an open-access article distributed under the terms of the Creative Commons Attribution License, which permits unrestricted use, distribution, and reproduction in any medium, provided the original author and source are credited. 
Citation: Sieda BM (2016) Comparative Study of the Clinical Outcome of Retrograde Laparoscopic Appendicectomy Using a Single Polymer Clip for Complicated Versus for Non-Complicated Appendicitis. Surgery Curr Res 6: 263. doi:10.4172/2161-1076.1000263

Page 2 of 5

inflamed or gangrenous appendicular base were excluded from clipping for patient safety and fear of cut through, another titanium or polymer clip applied distally. The appendix is transected between the proximal and distal clip, then the mesoappendix was divided using bipolar diathermy (Figures 5 and 6), in complicated appendicitis it was challenging for division of the thick inflamed mesoappendix. Patients have a Jackson-Pratt drain placed in the pelvis after completion of the appendectomy for complicated cases only. Postoperative analgesia administrated using paracetamol, Diclofenac and Morphine. Perioperative intravenous antibiotics are administered using 3rd generation cephalosporin. Patient initiated diet within 6 hours postoperatively except four patients, initiated after 24 hours.

\section{Data collection, parameter measured and follow-up}

Standardized data collection was performed on a prospective database, the data collected by the attending resident and attending physician and each patient were evaluated at the hospital outpatient clinic for 2 months. All patients before discharge and before giving the sick leave were requested to return to the outpatient clinic every week for the first months and every two weeks for the next month for a standardized examination and follow-up. All patients were assessed for postoperative pain, distension, fever, any signs of infection and port site infection.

\section{Statistical analysis}

Continuous variables were expressed as the mean \pm SD and median (range). The categorical variables were expressed as a number (percentage). Continuous variables were checked for normality by using Shapiro-Wilk test. Mann-Whitney U was used to compare two groups of non normally distributed data. Percent of categorical variables were compared using the Pearson's Chi-square test or Fisher's exact test when was appropriate. All test were two sided. $\mathrm{p}<0.05$ was considered statistically significant. All data were analyzed using Statistical Package for Social Science for windows version 18.0 (SPSS Inc., Chicago, IL, USA) \& MedCalc for windows version 13 (MedCalc Software bvba, Ostend, Belgium).

\section{Results}

Study began on August 2012 and concluded April 2014. 78 patients aged 18 years and above diagnosed with appendicitis were admitted to the unit, Only 60 patients formally approached of 78 patients, four old

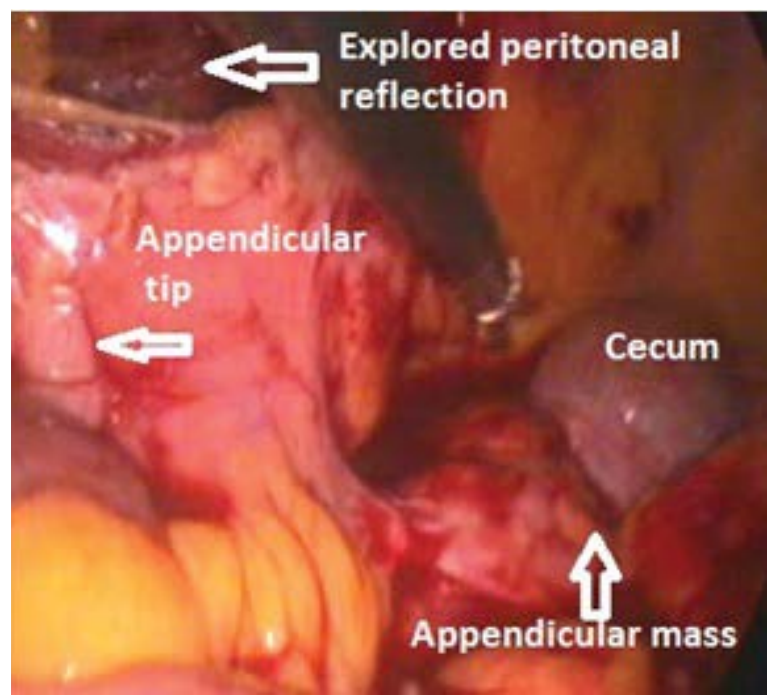

Figure 1: Appendicular mass. aged patients and sex pediatric population excluded, three patients were ineligible due to precious open abdominal surgery through midline, Five patients with gangrenous appendicular base. Sixty patients were eligible and agreed to take part in the study and they were randomized into two Groups.

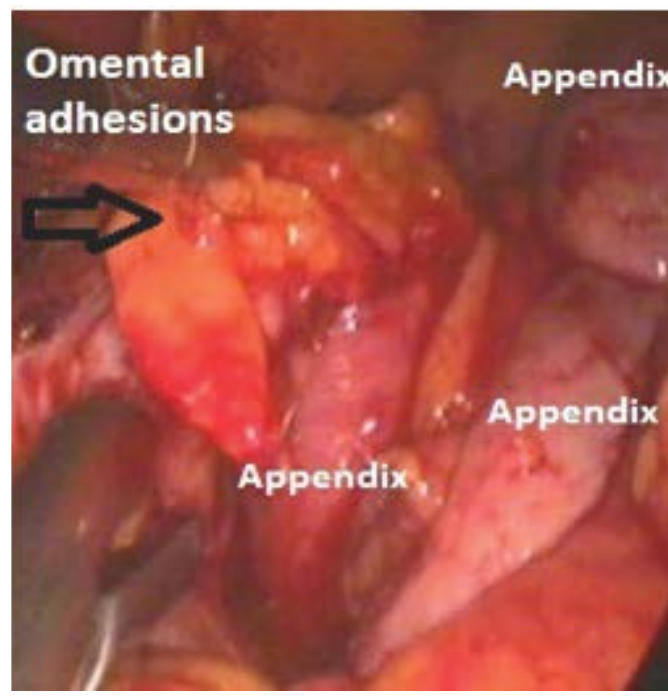

Figure 2: Appendicular mass.

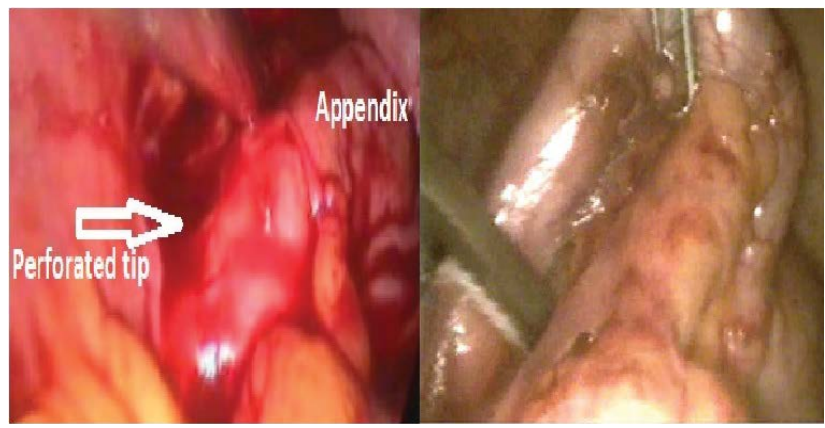

Figure 3: Perforated appendicular tip.

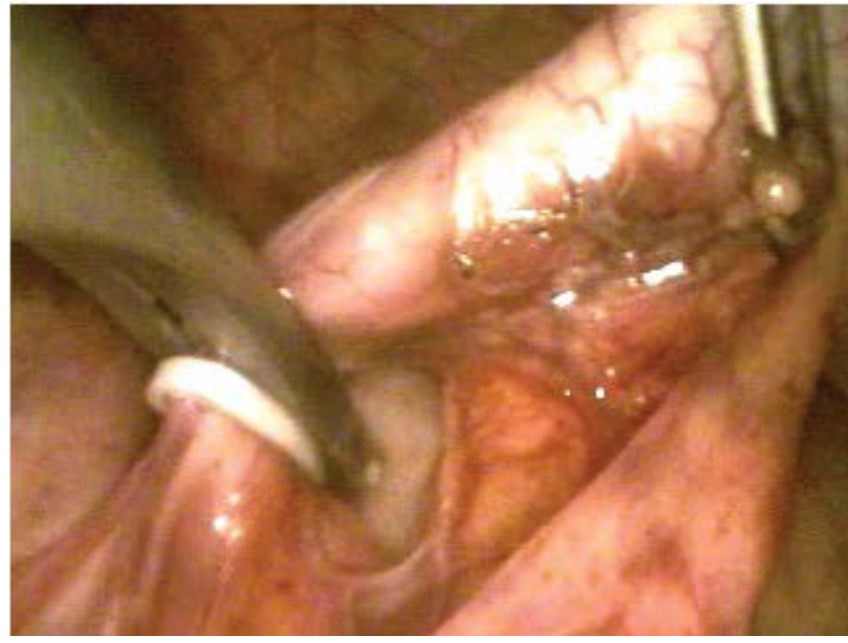

Figure 4: Single polymer clip. 
Citation: Sieda BM (2016) Comparative Study of the Clinical Outcome of Retrograde Laparoscopic Appendicectomy Using a Single Polymer Clip for Complicated Versus for Non-Complicated Appendicitis. Surgery Curr Res 6: 263. doi:10.4172/2161-1076.1000263

Page 3 of 5

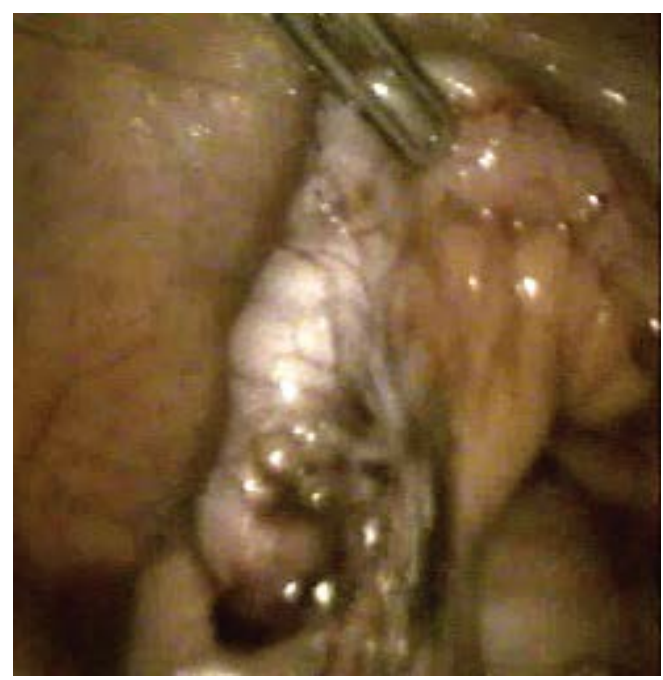

Figure 5: Meso-appendix.

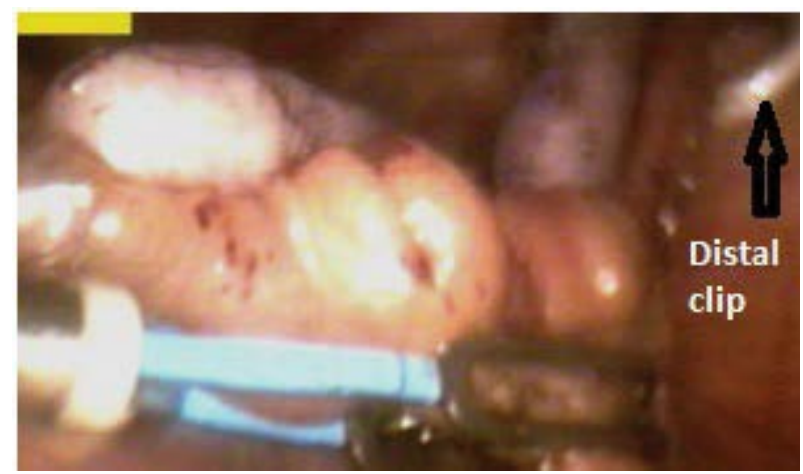

Figure 6: Bipolar + second clip

In Group I, 16 patients (61.5\%) male and 10 patients (30.8\%), were female underwent surgery. In Group II, 13(61.5\%) male and 21 patients $(61.8 \%)$, were female.

Patient age ranged from 18 to 41 years, where in Group I ranged from 24 to 41 with mean \pm SD $27.5 \pm 7.4$ years and in Group II ranged from 18 to 36 with a mean \pm SD $25.8 \pm 8.5$ years and the $\mathrm{P}$ value was $0.420 \ddagger$ (Table1).

Patients in Group I were 10 cases with appendicular mass (34.5\%), 8 cases with perforated appendix at the tip (30.8\%), four cases perforated shaft appendix (15.4\%) four cases with gangrenous appendix with healthy base (15.4\%).

On average, Laparoscopy for non-complicated cases was quicker with the total operation time being 15 minute shorter, with mean \pm SD $55.4 \pm 12.6$ minutes in Group I and mean \pm SD $40.5 \pm 10.5$ minutes in Group II, The P value was significant $<0.001 \ddagger$ (Table 2 ).

Outcomes, Conversion rate and Surgery related complication: The primary clinical outcome was severity of pain using the pain Numerical Rating Scale (NRS) at 1-7 days. Secondary outcomes included duration of operation (minutes), procedure related complication rates, conversion rates, hospital re-admission and time to return to normal activities.

\begin{tabular}{|c|c|c|c|}
\hline Age (years) & & & \\
\hline Mean \pm SD & $27.5 \pm 7.4$ & $25.8 \pm 8.5$ & 0.420 \\
\hline Median (range) & $27(24-41)$ & $25(18-36)$ & \\
\hline Sex & & & \multirow{2}{*}{0.073} \\
\hline Male & $16(61.5 \%)$ & $13(38.2 \%)$ & \\
\hline Female & $10(38.5 \%)$ & $21(61.8 \%)$ & \\
\hline
\end{tabular}

$\mathrm{N}=$ Total number of patients in each group; Quantitative data were expressed as the mean $\pm S D$.

Table 1: Baseline characteristics and demographic date.

\begin{tabular}{|c|c|c|c|}
\hline \multirow[b]{2}{*}{ Operative time } & \multicolumn{2}{|c|}{ Type of appendicitis } & \multirow[b]{2}{*}{ p-value } \\
\hline & $\begin{array}{l}\text { Complicated } \\
(\mathrm{N}=26)\end{array}$ & $\begin{array}{c}\text { Non complicated } \\
(\mathrm{N}=34)\end{array}$ & \\
\hline \multicolumn{4}{|l|}{$\begin{array}{l}\text { Operative time } \\
\text { (min.) }\end{array}$} \\
\hline Mean \pm SD & $55.4 \pm 12.6$ & $40.5 \pm 10.5$ & \multirow{2}{*}{$<0.001 \ddagger$} \\
\hline Median (range) & $50(40-70)$ & $42(30-65)$ & \\
\hline$<40$ minutes & $1(3.8 \%)$ & $17(50 \%)$ & $<0.001 \S$ \\
\hline $40-55$ minutes & $18(69.2 \%)$ & $12(35.3 \%)$ & $0.009 \S$ \\
\hline$\geq 55$ minutes & $7(26.9 \%)$ & $5(14.7 \%)$ & $0.241 \S$ \\
\hline
\end{tabular}

$\mathrm{N}=$ Total number of patients in each group; Quantitative data were expressed as the mean \pm SD; Qualitative data were expressed as a number (percentage); $\ddagger$ Mann Whitney U test; $\S$ Chi-square test; $p<0.05$ is significant.

Table 2: Operative time.

All cases were completed laparoscopically except four patients (15.4\%). In Group I, three patients converted to open technique, one patient had bleeding and field obscured. In the other two patients, there was marked difficulty in localizing the appendix where it was hidden into the large mass so we convert to open surgery. In Group II, one patient found to have inflamed meckels diverticulum with wide base necessitated resection, there is no statistical difference between two groups regarding conversion.

Four patients from the 60 patients $(15.4 \%)$ had postoperative complications. In Group I, three patients (11.5\%), developed intraabdominal abscess postoperatively. In Group II, one patient $(2.9 \%)$ developed port site infection. The difference in conversion rates and post-operative complication between two groups is statistically not significant with $\mathrm{P}$ value $>0.05$ (Table 3 ).

Patients developed intra-abdominal abscess postoperatively managed as follow, one of them underwent laparoscopic drainage during the same admission, the other two patients readmitted after one to two weeks, and one of them underwent US-guided drainage and the last one improved within 72 hours with the use of third-generation cephalosporin's and Metronidazole. Patient who developed port site infection was at the left mid-clavicular port, the patient improved with 3rd generation cephalosporin antibiotic and dressing.

No other complications were noted. None of these patients were readmitted for port site hernia nor postoperative bleeding. The postoperative course of all patients was uneventful except the patients that developed the postoperative intraabdominal abscess.

Morphine use during immediate recovery was less in participant in non-complicated group. Morphine dose was similar in both groups when given. There was no difference in the use of postoperative analgesia on the ward. Similarly, there was no statistical difference in patient-reported pain on days 1-7 (Table 4).

The mean length of hospital stay after surgery was $3.5 \pm 2.4$ days in Group I and $2.3 \pm 1.4$ in Group II. This is statistically not significant between the two Groups (Table 5). 
Citation: Sieda BM (2016) Comparative Study of the Clinical Outcome of Retrograde Laparoscopic Appendicectomy Using a Single Polymer Clip for Complicated Versus for Non-Complicated Appendicitis. Surgery Curr Res 6: 263. doi:10.4172/2161-1076.1000263

Page 4 of 5

\begin{tabular}{|c|c|c|c|c|}
\hline \multirow{2}{*}{$\begin{array}{l}\text { Technical difficulties and post-operative } \\
\text { complication }\end{array}$} & \multicolumn{2}{|c|}{ Type of appendicitis } & \multirow{2}{*}{ Difference - $(95 \% \mathrm{Cl})$} & \multirow{2}{*}{ p-value } \\
\hline & Complicated $(\mathrm{N}=\mathbf{2 6})$ & Non complicated $(\mathrm{N}=34)$ & & \\
\hline \multicolumn{5}{|l|}{ Technical difficulties } \\
\hline Bleeding & $1(3.8 \%)$ & $0(0 \%)$ & $3.8 \%(0 \%-10.4 \%)$ & 0.433 \\
\hline Trauma to neighboring & $0(0 \%)$ & $0(0 \%)$ & --- & 1 \\
\hline Difficult localization of appendix & $2(7.7 \%)$ & $0(0 \%)$ & $7.7 \% \quad(0 \%-17 \%)$ & 0.184 \\
\hline \multicolumn{5}{|l|}{ Post-operative complications } \\
\hline Port site infection & $0(0 \%)$ & $1(2.9 \%)$ & $2.9 \%(0 \%-3.6 \%)$ & 1 \\
\hline Port site hernia & $0(0 \%)$ & $0(0 \%)$ & --- & 1 \\
\hline Port site bleeding & $0(0 \%)$ & $0(0 \%)$ & -- & 1 \\
\hline Residual intra-abdominal abscess & $3(11.5 \%)$ & $0(0 \%)$ & $11.5 \%(0 \%-22.9 \%)$ & 0.076 \\
\hline
\end{tabular}

$\mathrm{N}=$ Total number of patients in each group; Qualitative data were expressed as a number (percentage); $95 \% \mathrm{Cl}$ : $95 \% \mathrm{confidence} \mathrm{interval;} \mathrm{p}<0.05$ is significant.

Table 3: Complication and causes of conversion.

\begin{tabular}{|c|c|c|c|c|}
\hline \multirow{2}{*}{$\begin{array}{l}\text { Postoperative pain and use of } \\
\text { analgesia }\end{array}$} & \multicolumn{2}{|c|}{ Type of appendicitis } & \multirow{2}{*}{ Difference- $(95 \% \mathrm{Cl})$} & \multirow{2}{*}{ p-value } \\
\hline & Complicated $(\mathrm{N}=26)$ & Non complicated $(\mathrm{N}=34)$ & & \\
\hline \multicolumn{5}{|c|}{ Post operative analgesia in recovery room } \\
\hline Paracetamol & $12(46.2 \%)$ & $19(55.9 \%)$ & $9.7 \%(0 \%-26.9 \%)$ & \multirow{2}{*}{0.455} \\
\hline Morphine & $14(53.8 \%)$ & $15(44.1 \%)$ & $9.7 \% \quad(0 \%-45.2 \%)$ & \\
\hline \multicolumn{5}{|l|}{ Post operative analgesia in ward } \\
\hline Paracetamol & $10(38.5 \%)$ & $19(55.9 \%)$ & $17.4 \%(0 \%-18.1 \%)$ & 0.181 \\
\hline Diclofenac & $14(53.8 \%)$ & $15(44.1 \%)$ & $9.7 \% \quad(0 \%-45.2 \%)$ & 0.455 \\
\hline Morphine & $2(7.7 \%)$ & $0(0 \%)$ & $7.7 \% \quad(0 \%-17 \%)$ & 0.184 \\
\hline \multicolumn{5}{|c|}{ Patient reported pain during 1-7 days post-operation } \\
\hline No pain & $4(15.4 \%)$ & $7(20.6 \%)$ & $5.2 \% \quad(0 \%-16.6 \%)$ & 0.742 \\
\hline Pain when resting & $10(38.5 \%)$ & $18(52.9 \%)$ & $14.4 \% \quad(0 \% 20.4 \%)$ & 0.265 \\
\hline Pain when moving & $12(46.2 \%)$ & $9(26.5 \%)$ & $19.6 \% \quad(0 \%-49.8 \%)$ & 0.113 \\
\hline
\end{tabular}

$\mathrm{N}=$ Total number of patients in each group; Qualitative data were expressed as a number (percentage); $95 \% \mathrm{Cl}$ : $95 \%$ confidence interval; $\mathrm{p}<0.05$ is significant.

Table 4: Postoperative pain and use of analgesia.

\begin{tabular}{|c|c|c|c|}
\hline \multirow{2}{*}{ Hospital stay } & \multicolumn{2}{|c|}{ Hospital stay } & \multirow{2}{*}{ p-value } \\
\hline & Complicated $(\mathrm{N}=26)$ & Non complicated $(\mathrm{N}=34)$ & \\
\hline \multicolumn{4}{|c|}{ Holiday stay (days) } \\
\hline Mean \pm SD & $3.5 \pm 2.4$ & $2.3 \pm 1.4$ & \multirow{2}{*}{0.018} \\
\hline Median (range) & $2(1-6)$ & $1(1-4)$ & \\
\hline 1 day & $22(84.5 \%)$ & $33(97.1 \%)$ & 0.156 \\
\hline $2-3$ days & $0(0 \%)$ & $0(0 \%)$ & 1 \\
\hline$>3$ days & $4(15.3 \%)$ & $1(2.9 \%)$ & 0.156 \\
\hline
\end{tabular}

$\mathrm{N}=$ Total number of patients in each group; Quantitative data were expressed as the mean $\pm \mathrm{SD}$; Qualitative data were expressed as a number (percentage); $\mathrm{p}<0.05$ is significant.

Table 5: Hospital stay.

Initiation of diet: Patients initiated diet as tolerated (DAT) within 6 hours from operation except four patients, Two of them presented with ileus due to proved intra-abdominal abscess, the other patients started oral after 24 hour and this was the patients converted to open technique whose has difficulty dissecting the appendicular mass.

\section{Discussion}

Laparoscopic appendicectomy is still a matter of concern for complicated appendicitis; our study main objective was to prove the technical feasibility of laparoscopy for complicated as well as noncomplicated appendicitis using retrograde approach. Laparoscopy can be a main therapeutic procedure than open appendicitis in complicated and non-complicated cases and this is comparable with many studies [9]. Other studies still recommended the open approach for complicated appendicitis when confirmed well with imaging studies. This is not issued in our study where most of those cases (84.6\%) were successfully treated laparoscopically[10].

Preoperative CT abdomen and pelvis are of utmost importance to confirm diagnosis of complicated appendicitis specially and this was comparable with many studies where they necessitate the role of CT and Alvarado scoring system to decrease a rate of negative appendicectomy[11,12].

Many updated studies recommended immediate surgery for appendicular mass by open surgery versus laparoscopic approach and using a single incision adds a more and more advantage to the laparoscopic approach as early operation on the other hand has the benefit of being curative in the index admission and ensures early 
Citation: Sieda BM (2016) Comparative Study of the Clinical Outcome of Retrograde Laparoscopic Appendicectomy Using a Single Polymer Clip for Complicated Versus for Non-Complicated Appendicitis. Surgery Curr Res 6: 263. doi:10.4172/2161-1076.1000263

return- to-work and higher compliance, and this agree with our study but we used 3 port instead of the single port $[13,14]$.

Conversion to open technique is not a sign of failure but we documented a four cases converted to open technique (4\%) in both groups and documented no significant statistical difference between the two groups and this is comparable with a study was done by Taylor et al. [15], who reported a 5.5\% conversion rate but his study was conducted for pediatric population whose ages ranged from eleven to fifteen years old which is a lesser than our patient's ages.

We reported an incidence of $11.5 \%$ in postoperative intraabdominal abscess, the accepted percentage was supported by the use of the accepted method of dissection by the retrograde approach and the use of the easy applicable single Hem-O-lock clip polymer clip, only one proximal clip ensure complete lumen closure as strong as 2 clips but it is advantageous over 2 clips in being less time consuming and less cost, all of which may provide greater security, its disadvantage is that the lock of the clip is very strong and can cause cut through if used over markedly inflamed or friable tissue. Another disadvantage is the lacking of radio-opaque material which is not a matter of concern in laparoscopic appendicectomy but critique in biliary surgery.

In a study done by Yagnik et al. [16], a total of 452 patients were operated with classic antegrade laparoscopic appendicectomy. There was 362 (80.1\%) uncomplicated appendicitis (Group I) and 90 (19.1\%) complicated appendicitis Group (II). The intraabdominal abscess rate was $14.35 \%$ in Group I and $19.5 \%$ in Group II. This incidence is higher than our incidence. In another study, conducted and reported by Nasher et al. [17], comparing retrograde LA to open appendectomy for complicated cases in a younger age group, no IAA occurred after LA. In other studies overall infection rate including surgical site infection and IAA was $2.54 \%$ in uncomplicated cases and $7.32 \%$ in complicated cases and these results were better than our results[18].

Partecke et al., [19] had a prospective randomized study on 101 patients over a 1 year study period for both complicated and uncomplicated cases; a single Hem-o-lock ML-LX polymeric clip was applied. He found that less incidence of postoperative intra-abdominal abscesses and surgical site infection (8.9\%) and he attribute his results to both the laparoscopy and the single polymer clip used. It is partially similar to our study but we used less number of patients in a larger period of time. Also comparable with Hue et al. and Cho et al. [20,21] who confirmed the safety of polymer clip usage in laparoscopic appendicectomy for complicated appendix.

\section{Conclusion and Recommendation}

Laparoscopic retrograde appendicectomy is technically feasible, allow easy access to the appendix and avoid excessive unnecessary dissection in complicated appendicitis and results were accepted especially with the use of single polymer clips which ensure secure closure of stump in complicated as well as uncomplicated appendicitis.

\section{Acknowledgements}

Great thanks for our senior staff for their continuous recommendations, also we thank junior colleagues and nursing staff and all personnel who assisted in this work.

\section{References}

1. Kehagias I, Karamanakos SN, Panagiotopoulos S, Konstantinos KP, Kalfarentzos F (2008) Laparoscopic versus open appendectomy: which way to go?. Worlf J Gastroenterol 14: 4909-4914.

2. Ingraham AM, Cohen ME, Bilimoria KY, Pritts TA, Ko CY, et al. (2010) Comparison of outcomes after laparoscopic versus open appendectomy for acute appendicitis at 222 ACS NSQIP hospitals. Surgery 148: 625-635.
3. Wu SC, Wang YC, Fu CY, Chen RJ, Huang HC, et al. (2011) Laparoscopic appendectomy provides better outcomes than open appendectomy in elderly patients. Am Surg 77: 466-470.

4. Bachar I, Perry ZH, Dukhno L, Mizrahi S, Kirshtein B (2013) Diagnostic value of laparoscopy, abdominal computed tomography, and ultrasonography in acute appendicitis. J Laparoendosc Adv Surg Tech A 23: 982-989.

5. Rehman H, Rao AM, Ahmed I (2011) Single incision versus conventional multiincision appendicectomy for suspected appendicitis. Cochrane database syst Rev 6: 7-11.

6. Markar SR, Blackburn S, Cobb R, Karthikesalingam A, Evans J, et al. (2012) Laparoscopic versus open appendectomy for complicated and uncomplicated appendicitis. J Gastrointest Surg. 16: 1993-2004.

7. Swank HA, Eshuis EJ, van Berge Henegouwen MI, Bemelman WA(2011) Short- and Long-Term Results of Open Versus Laparoscopic Appendectomy. World J Surg 5: 1221-1226.

8. Akkoyun I, Akbiyik F (2012) Closing the appendicular stump with a polymeric clip in laparoscopic appendectomy. Eur J Pediatr Surg 22: 133-135.

9. Raja AS, Wright C, Sodickson AD, Zane RD, Schiff GD, et al. (2010) Negative appendectomy rate in the era of CT (an 18-year perspective). Radiology 256: 460-465.

10. Arshad M, Aziz LA, Qasim M, Talpur KA(2008) Early appendicectomy in appendicular mass -a Liaquat University Hospital experience. J Ayub Med Coll Abbottabad 20: $70-72$

11. Rasheed A, Al-Harthy M, Obeid Dhafar Kh, Maimini O, Abdul Sattar Shaker H (2011) Alvarado score and appendicitis. Hellenic Journal of Surgery 83: 197-201.

12. Tan WJ, Acharyya S, Goh YC, Chan WH, Wong WK et al. (2014) Prospective Comparison of the Alvarado Score and CT Scan in the Evaluation of Appendicitis. A proposed Algorithm to Guide CT use. J am coll surg 10: 1-10.

13. Bat O, Kaya H, Celik HK, Sahbaz NA (2014) Clinical results of laparoscopic appendectomy in patients with complicated and uncomplicated appendicitis. Int J Clin Exp Med 7: 3478-3481.

14. Lin HF, Lai HS, Lai IR (2014) Laparoscopic treatment of perforated appendicitis. World J Gastroenterol 20: 338-347.

15. Taylor GA (2014) Abdominal ultrasound is specific but insufficiently sensitive for diagnosing appendicitis. J Pediat 164: 672-673.

16. Yagnik VD, Rathod JB, Phatak AG (2010) A retrospective study of two-port appendectomy and its comparison with open appendectomy and three port appendectomy. Saudi J Gastroenterol 16: 268-271.

17. Nasher O, Patel RV, Singh SJ (2013) Retrograde trans-meso-appendicular selective sub-serosal laparoscopic appendicectomy. Journal of Pediatric Surgery Case Reports 1: $50-52$.

18. Yano H, Murakami M, Nakano Y, Tone T, Ohnishi T, et al. (2004) Laparoscopic treatment for perforated appendicitis with pelvic abscess. Digestive endoscopy 16: 343-346.

19. Partecke LI, Kessler W, Von Bernstorff W, Diedrich S, Heidecke CD, et al. (2010) Laparoscopic appendectomy using a single polymeric clip to close the appendicular stump. Langenbecks Arch Surg 395: 1077-1082.

20. Hue CS, Kim JS, Kim KH, Nam SH, Kim KW (2013) The usefulness and safety of Hem-O- lock clips for the closure of appendicular stump during laparoscopic appendectomy. J Korean Surg Soc 84: 27-32.

21. Cho J, Park I, Lee D, Sung K Baek J, et al. (2015) Risk Factors for Postoperative IntraAbdominal Abscess after Laparoscopic Appendectomy: Analysis for Consecutive 1,817 Experiences. Dig Surg 32: 375-381. 